\title{
SK Channels Regulate Resting Properties and Signaling Reliability of a Developing Fast-Spiking Neuron
}

\author{
Yihui Zhang ${ }^{1}$ and ${ }^{-H}$ Hai Huang ${ }^{1,2}$ \\ ${ }^{1}$ Department of Cell and Molecular Biology and ${ }^{2}$ Brain Institute, Tulane University, New Orleans, Louisiana 70118
}

Reliable and precise signal transmission is essential in circuits of the auditory brainstem to encode timing with submillisecond accuracy. Globular bushy cells reliably and faithfully transfer spike signals to the principal neurons of the medial nucleus of the trapezoid body (MNTB) through the giant glutamatergic synapse, the calyx of Held. Thus, the MNTB works as a relay nucleus that preserves the temporal pattern of firing at high frequency. Using whole-cell patch-clamp recordings, we observed a $\mathrm{K}^{+}$conductance mediated by smallconductance calcium-activated potassium (SK) channels in the MNTB neurons from rats of either sex. SK channels were activated by intracellular $\mathrm{Ca}^{2+}$ sparks and mediated spontaneous transient outward currents in developing MNTB neurons. SK channels were also activated by $\mathrm{Ca}^{2+}$ influx through voltage-gated $\mathrm{Ca}^{2+}$ channels and synaptically activated NMDA receptors. Blocking SK channels with apamin depolarized the resting membrane potential, reduced resting conductance, and affected the responsiveness of MNTB neurons to signal inputs. Moreover, SK channels were activated by action potentials and affected the spike afterhyperpolarization. Blocking SK channels disrupted the one-to-one signal transmission from presynaptic calyces to postsynaptic MNTB neurons and induced extra postsynaptic action potentials in response to presynaptic firing. These data reveal that SK channels play crucial roles in regulating the resting properties and maintaining reliable signal transmission of MNTB neurons.

Key words: excitability; MNTB; potassium channel; resting membrane potential; SK channel; transmission fidelity

\section{Significance Statement}

Reliable and precise signal transmission is required in auditory brainstem circuits to localize the sound source. The calyx of Held synapse in the mammalian medial nucleus of the trapezoid body (MNTB) plays an important role in sound localization. We investigated the potassium channels that shape the reliability of signal transfer across the calyceal synapse and observed a potassium conductance mediated by small-conductance calcium-activated potassium (SK) channels in rat MNTB principal neurons. We found that SK channels are tonically activated and contribute to the resting membrane properties of MNTB neurons. Interestingly, SK channels are transiently activated by calcium sparks and calcium influx during action potentials and control the one-to-one signal transmission from presynaptic calyces to postsynaptic MNTB neurons.

\section{Introduction}

Sound source localization by the mammalian auditory system is accomplished via the binaural comparison of the timing and strength of sound detected at each ear (Grothe et al., 2010). The reliability and precision of signal transmission are required in circuits of the auditory brainstem to encode timing with submil-

Received May 6, 2017; revised Sept. 7, 2017; accepted Sept. 27, 2017.

Author contributions: Y.Z. and H.H. designed research; Y.Z. and H.H. performed research; Y.Z. and H.H. analyzed data; Y.Z. and H.H. wrote the paper.

This work was supported by the U.S. National Institutes of Health Grant DC012063 to H.H. We thank Drs. Laura Schrader, Jeffrey Tasker, Laurence Trussell, and Youad Darwish, for critical reading and comments on this manuscript, and Dr. Hsin-Wei Lu, for advice on data analysis.

The authors declare no competing financial interests.

Correspondence should be addressed to Hai Huang, PhD, Department of Cell and Molecular Biology, Tulane University, 2000 Percival Stern Hall, 6400 Freret Street, New Orleans, LA 70118. E-mail: hhuang5@tulane.edu.

DOI:10.1523/JNEUROSCI.1243-17.2017

Copyright $\odot 2017$ the authors $\quad 0270-6474 / 17 / 3710738-10 \$ 15.00 / 0$ lisecond accuracy for sound localization (Trussell, 1997). The medial nucleus of trapezoid body (MNTB) of the superior olivary complex plays important roles in sound localization. The MNTB principal neurons are glycinergic/GABAergic. They receive excitatory glutamatergic inputs from contralateral globular bushy cells (GBCs) in the anterior ventral cochlear nucleus and send inhibitory projections to the lateral superior olivary (LSO) neurons (Smith et al., 1991). LSO neurons also receive excitatory inputs from the ipsilateral spherical bushy cells. The computation of excitatory signals from the ipsilateral ear and inhibitory signals from the contralateral ear provides the initial point for interaural level difference processing (Tollin, 2003).

GBCs reliably transmit high-frequency signals to principal neurons of the contralateral MNTB through the giant glutamatergic nerve terminal, the calyx of Held (von Gersdorff and Borst, 2002). The calyx-MNTB synapse features high-fidelity synaptic transmission that preserves the temporal pattern of firing at fre- 


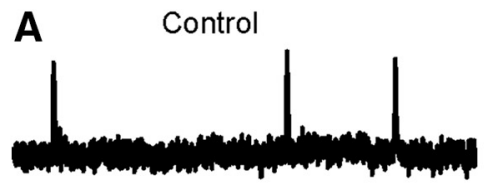

Apamin

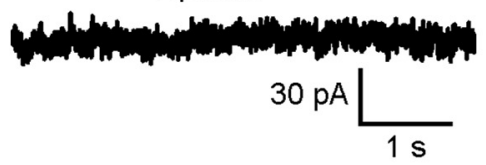

D
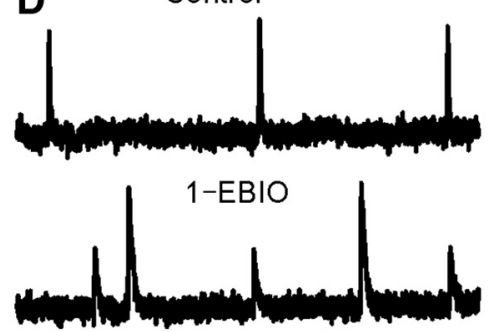

$30 \mathrm{pA}$
B

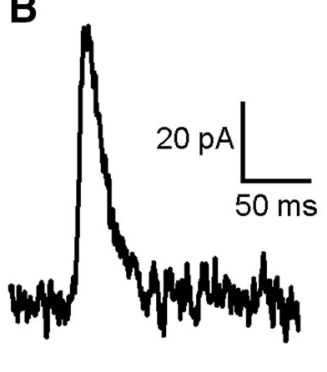

$\mathbf{E}$

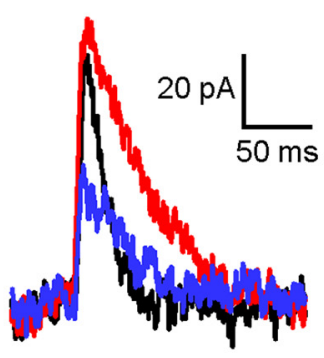

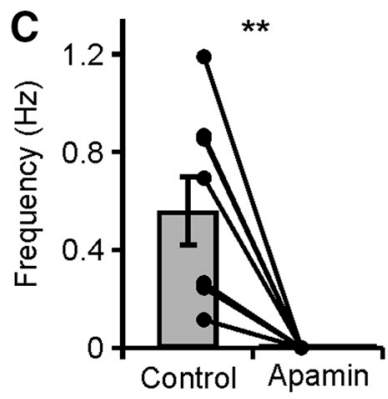

$\mathbf{F}$

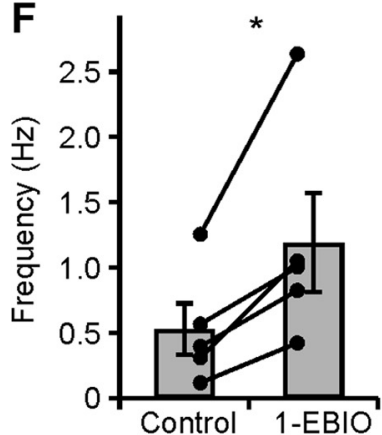

G

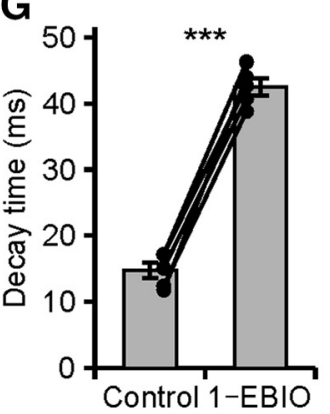

H

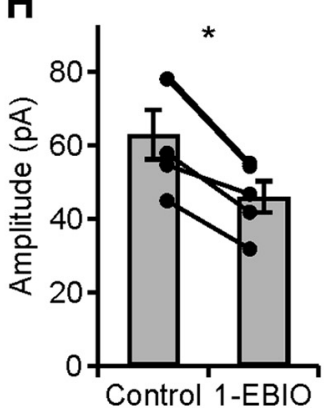

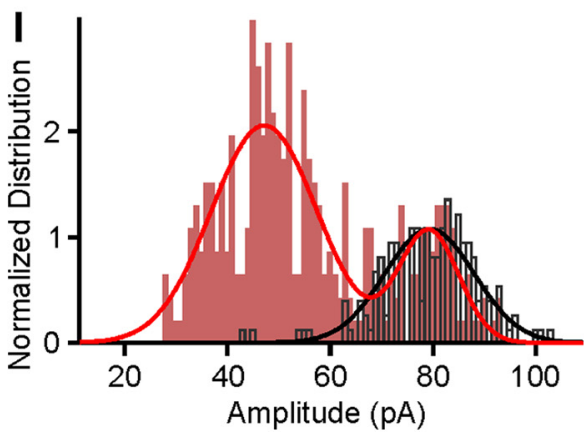

Figure 1. SK channels mediated STOCS. A, STOC recordings in control and after bath application of $100 \mathrm{~nm}$ apamin. $\boldsymbol{B}$, A representative STOC event. C, Summarized data of apamin effects on the STOC frequency. D, STOC recordings in control and after bath application of $100 \mu \mathrm{M}$ 1-EBIO. E, Representative STOC events in control condition (black) and in the presence of 1-EBI0 with different amplitudes (red and blue). $\boldsymbol{F}-\boldsymbol{H}$, Summarized data of 1 -EBIO effects on STOC frequency $(\boldsymbol{F})$, decay time $(\boldsymbol{G})$, and amplitude $(\boldsymbol{H})$. $\boldsymbol{I}$, Amplitude distributions of STOCs recorded in the absence (black) and presence (red) of 1-EBI0, which were fit with one-component (black) and two-component (red) Gaussian functions, respectively. MNTB neurons were voltage-clamped at $-65 \mathrm{mV}$. Recordings were made in the presence of $50 \mu \mathrm{m}$ picrotoxin, $1 \mu \mathrm{m}$ strychnine, $20 \mu \mathrm{m} \mathrm{DNQX}$, and $50 \mu \mathrm{m} \mathrm{APV} \mathrm{to} \mathrm{block} \mathrm{the} \mathrm{GABA,} \mathrm{glycine,} \mathrm{AMPA,} \mathrm{and} \mathrm{NMDA} \mathrm{receptors,} \mathrm{respectively.}{ }^{*} p<0.05$; ${ }^{* *} p<0.01 ;{ }^{* * *} p<$ 0.001; paired Student's $t$ test; error bars are mean \pm SEM.

A

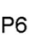

P8

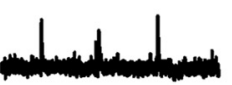

P10

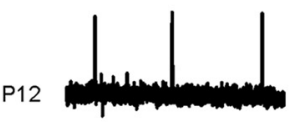

P14

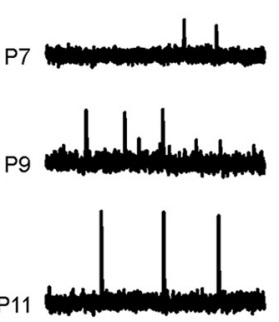

P13

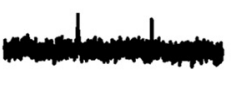

$20 \mathrm{pAL}$
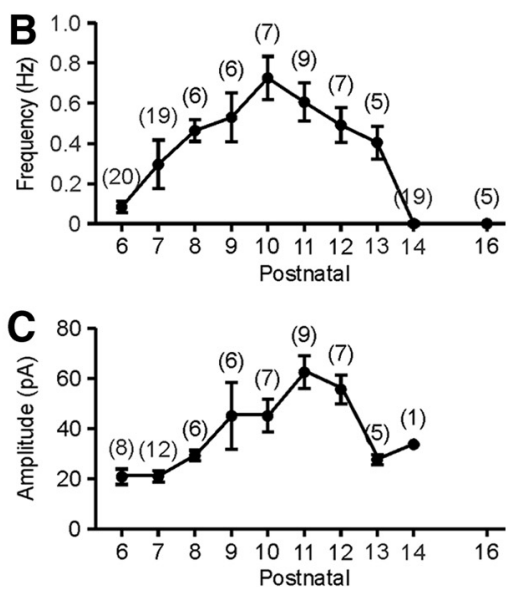

Figure 2. Development change of STOCS. $A$, Representative STOC recordings in rat MNTB neurons from P6 to P14. $\boldsymbol{B}, \boldsymbol{C}$, Summary data of STOC frequency $(\boldsymbol{B})$ and amplitude $(\boldsymbol{C})$ change during development. Only cells with STOCs were included in the amplitude plot.

quencies up to hundreds of hertz (Taschenberger and von Gersdorff, 2000; Lorteije et al., 2009; Borst and Soria van Hoeve, 2012). Both presynaptic and postsynaptic mechanisms contribute to the reliable one-to-one neurotransmission at such a high rate. For example, the calyceal terminal possesses hundreds of active zones with low release probability, ensuring reliable release of the neurotransmitter glutamate; the fast kinetics of postsynaptic AMPA-type glutamate receptors allows rapid transmission to the postsynaptic MNTB neurons; different voltage-gated $\mathrm{K}^{+}$channels are expressed on the presynaptic and postsynaptic components to determine spike threshold and shape, control the neuronal excitability, and enable high-frequency firing (Taschenberger and von Gersdorff, 2000; Taschenberger et al., 2002; Borst and Soria van Hoeve, 2012; Yang et al., 2014). 

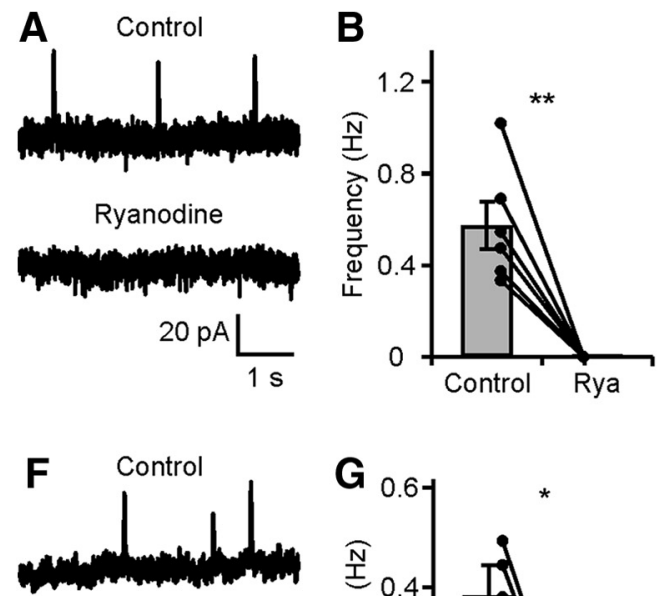

EGTA $(10 \mathrm{mM})$
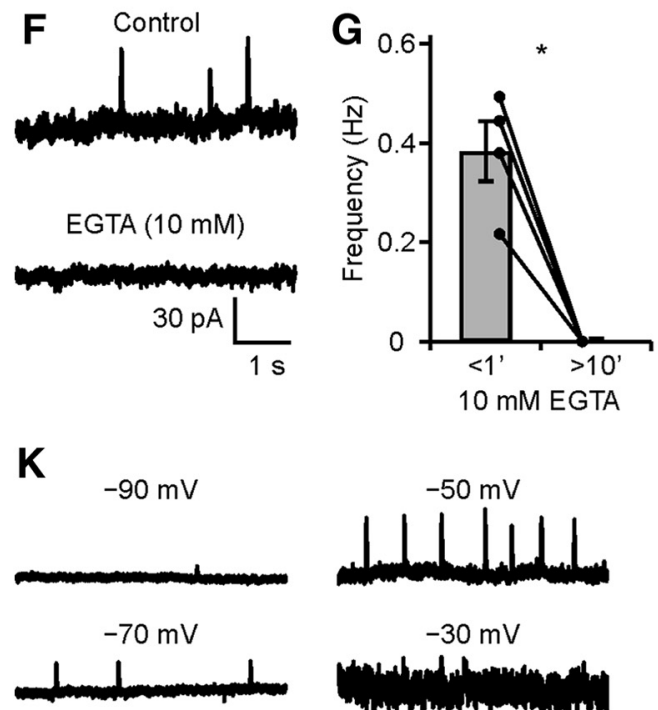

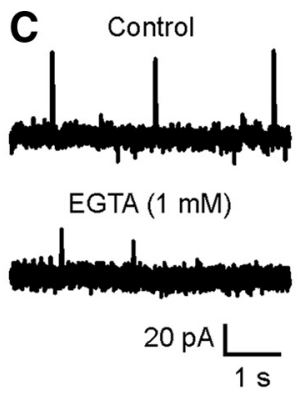

D
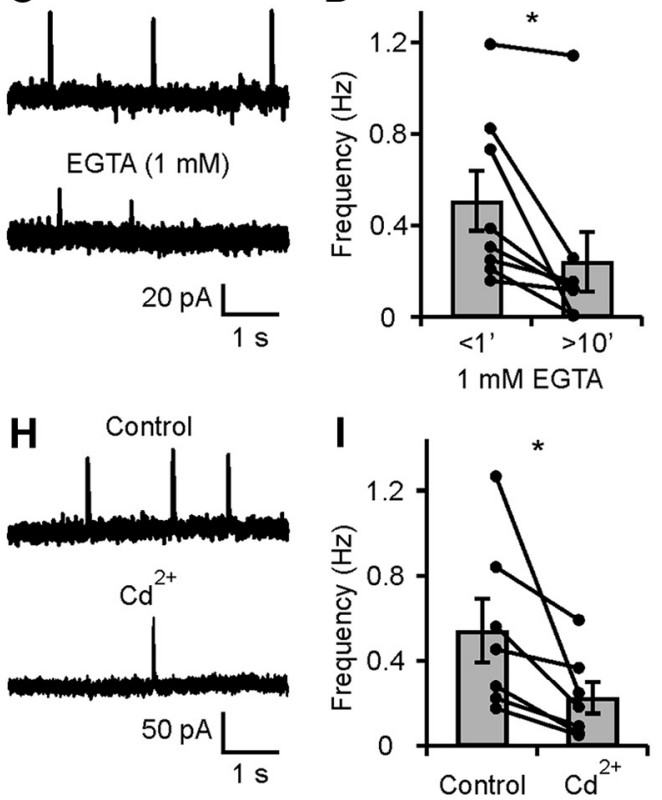
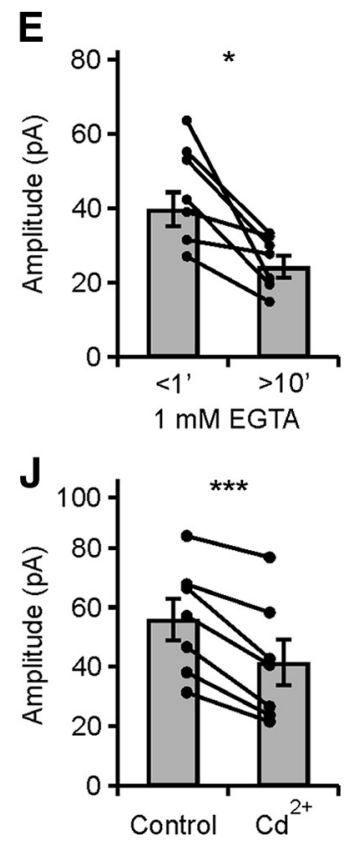
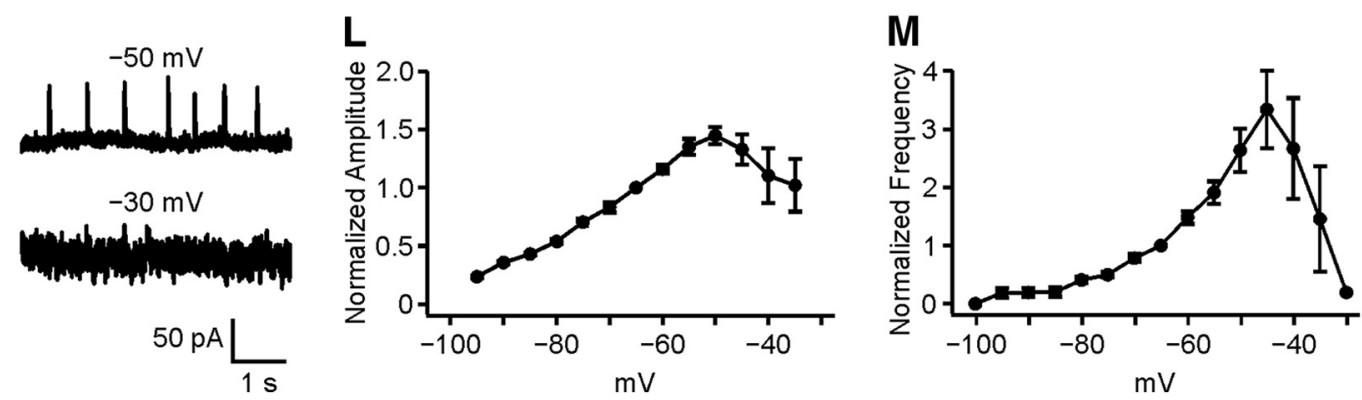

Figure 3. Calcium sparks activated the transient SK current. A, STOC recordings in control and after bath application of $20 \mu \mathrm{m}$ ryanodine. B, Ryanodine completely blocked the STOCS. C, STOC recordings immediately ( $<1 \mathrm{~min}$, control) and $>10 \mathrm{~min}$ (EGTA) after break into a pipette solution containing $1 \mathrm{~mm}$ EGTA. D,E, $1 \mathrm{~mm}$ EGTA decreased both the frequency and amplitude of the STOCS. $\boldsymbol{F}$, Same as Cexcept the EGTA concentration was $10 \mathrm{~mm}$. G, The STOCs were eliminated by $10 \mathrm{~mm}$ EGTA. $\boldsymbol{H}$, STOC recordings in control conditions and after bath application of $200 \mu \mathrm{m}$ CdCl . I, J, STOC frequency and amplitude were decreased by $\mathrm{Cd}^{2+} . \boldsymbol{K}$, Representative STOC recordings under different holding potentials. $\boldsymbol{L}, \boldsymbol{M}$, Normalized amplitude $(\boldsymbol{L})$ and frequency $(\boldsymbol{M})$ of STOCs under different holding potentials from -100 to $-30 \mathrm{mV}$ at $5 \mathrm{mV}$ increments, normalized to the values at $-65 \mathrm{mV} .{ }^{*} p<0.05 ;{ }^{* *} p<0.01$; ${ }^{* * *} p<0.001$; paired Student's $t$ test; error bars are mean \pm SEM.

We investigated the $\mathrm{K}^{+}$channels that shape the reliability of signal transfer across the calyx-MNTB synapse and observed a potassium conductance mediated by small-conductance $\mathrm{Ca}^{2+}$ activated $\mathrm{K}^{+}(\mathrm{SK})$ channels in rat MNTB neurons. SK channels are voltage-independent $\mathrm{K}^{+}$channels activated by submicromolar concentrations of cytosolic $\mathrm{Ca}^{2+}$ (Blatz and Magleby, 1986; Xia et al., 1998). We found that SK channels are tonically activated and control the resting membrane properties of MNTB neurons and affect their response to signal inputs. SK channels are also transiently activated by $\mathrm{Ca}^{2+}$ sparks and $\mathrm{Ca}^{2+}$ influx during action potentials and support the one-to-one spike transmission from presynaptic calyces to postsynaptic MNTB neurons.

\section{Materials and Methods}

Slice preparation. The handling and care of animals were approved by the Institutional Animal Care and Use Committee of Tulane University and complied with U.S. Public Health Service guidelines. Brainstem slices containing the MNTB were prepared from postnatal day (P) 6-P16 Wistar rats of either sex as previously described (Huang and Trussell, 2014). Briefly, $210 \mu \mathrm{m}$ sections were cut in ice-cold, low-Ca ${ }^{2+}$, low- $\mathrm{Na}^{+}$ saline using a Vibratome (VT1200S, Leica), incubated at $32^{\circ} \mathrm{C}$ for $20-40$ min in normal artificial CSF (aCSF) and thereafter stored at room temperature before use. The saline for slicing contained (in $\mathrm{mM}$ ) 230 sucrose, 25 glucose, $2.5 \mathrm{KCl}, 3 \mathrm{MgCl}_{2}, 0.1 \mathrm{CaCl}_{2}, 1.25 \mathrm{NaH}_{2} \mathrm{PO}_{4}, 25 \mathrm{NaHCO}_{3}, 0.4$ ascorbic acid, 3 myo-inositol, and $2 \mathrm{Na}$-pyruvate, bubbled with $5 \% \mathrm{CO}_{2} /$ $95 \% \mathrm{O}_{2}$. The aCSF for incubation and recording contained (in mM) 125 $\mathrm{NaCl}, 25$ glucose, $2.5 \mathrm{KCl}, 1.2 \mathrm{CaCl}_{2}, 1.8 \mathrm{MgCl}_{2}, 1.25 \mathrm{NaH}_{2} \mathrm{PO}_{4}, 25$ $\mathrm{NaHCO}_{3}, 0.4$ ascorbic acid, 3 myo-inositol, and 2 Na-pyruvate, $\mathrm{pH}$ 7.4, bubbled with $5 \% \mathrm{CO}_{2} / 95 \% \mathrm{O}_{2}$.

Whole-cell recordings. Brain slices were transferred to a recording chamber and were continually perfused with aCSF $(2-3 \mathrm{ml} / \mathrm{min})$ warmed to $\sim 32^{\circ} \mathrm{C}$ by an in-line heater (Warner Instruments). Neurons were viewed using an Olympus BX51 microscope with infrared Dodt gradient contrast optics and a $40 \times$ water-immersion objective. Whole-cell current-clamp and voltage-clamp recordings were made with a Multiclamp 700B amplifier (Molecular Devices). Pipette solution contained (in mM) $135 \mathrm{~K}$-gluconate, $10 \mathrm{KCl}, 4 \mathrm{MgATP}, 0.3$ Tris-GTP, $7 \mathrm{Na}_{2}$-phosphocreatine, 0.2 EGTA, 10 HEPES, 290 mOsm, pH 7.3 with KOH, except otherwise noted. In some recordings as indicated, the EGTA concentration was increased to 1 or $10 \mathrm{~mm}$ by substituting for K-gluconate with equal osmolarity. Pipettes pulled from thick-walled borosilicate glass capillaries (WPI) had open tip resistances of 2-4 M $\Omega$. Series resistances (4-15 M $\Omega$ ) were compensated by $60-80 \%$ (bandwidth $3 \mathrm{kHz}$ ).

To examine the SK activation under voltage-ramp and voltage-step experiments, tetrodotoxin (TTX; $0.5 \mu \mathrm{M}$ ), margatoxin (10 nM), and CsCl ( $2 \mathrm{~mm}$ ) were added to block the $\mathrm{Na}^{+}, \mathrm{Kvl}$, and hyperpolarizationactivated cyclic nucleotide-gated (HCN) channels, respectively, which enhanced space clamp and provided stable recordings. 

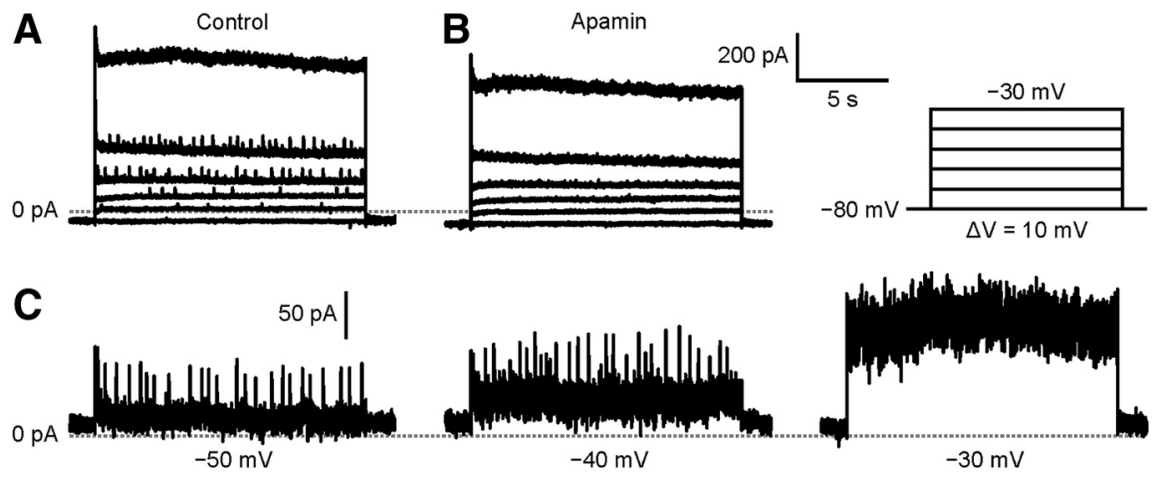

Figure 4. Tonic SK current. $\boldsymbol{A}, \boldsymbol{B}$, Depolarizing voltage steps ( $15 \mathrm{~s}$ ) from a holding potential of -80 to $-30 \mathrm{mV}$ in increments of $10 \mathrm{mV}$ evoked outward currents in control $(\boldsymbol{A})$ and after bath application of $100 \mathrm{~nm}$ apamin $(\boldsymbol{B})$. $\boldsymbol{C}$, Apamin-sensitive currents at different holding voltages obtained by subtracting the traces in $\boldsymbol{B}$ from that of $\boldsymbol{A}$, showing the activation of tonic SK current along with the STOCs. Recordings were made in the presence of $\operatorname{TTX}(0.5 \mu \mathrm{m})$, margatoxin (10 nM), and CsCl (2 mm) to block the Na ${ }^{+}, \mathrm{Kv1}_{\text {, }}$ and HCN channels, respectively.

To isolate the transient SK currents, picrotoxin $(50 \mu \mathrm{M})$, strychnine $(1 \mu \mathrm{M})$, DNQX $(20 \mu \mathrm{M}),(\mathrm{R})$-CPP $(5 \mu \mathrm{M})$, and TTX $(0.5 \mu \mathrm{M})$ were added to the recording solution to block the GABA, glycine, AMPA, and NMDA receptors, and voltage-gated $\mathrm{Na}^{+}$-channel-mediated current, respectively. $\mathrm{CaCl}_{2}$ and $\mathrm{MgCl}_{2}$ were adjusted to 2.0 and $1.0 \mathrm{~mm}$, respectively.

EPSCs were evoked by using a bipolar electrode positioned to the midline. To record NMDA-receptor-mediated EPSCs, strychnine $(1 \mu \mathrm{M})$, picrotoxin $(50 \mu \mathrm{M})$, and NBQX $(20 \mu \mathrm{M})$ were added to the recording solution. For AMPA-receptor-mediated EPSC recordings, pipettes contained (in mM) 130 Cs-methanesulfonate, $10 \mathrm{CsCl}, 10$ HEPES, 5 EGTA, 0.3 Tris-GTP, $4 \mathrm{Mg}$-ATP, $5 \mathrm{Na}_{2}$-phosphocreatine, and $2 \mathrm{QX}-314$, $289 \mathrm{mOsm}, \mathrm{pH} 7.3$, with CsOH. Strychnine $(1 \mu \mathrm{M})$, picrotoxin $(50 \mu \mathrm{M})$, and (R)-CPP (5 $\mu \mathrm{M})$ were added to the recording solution.

Signals were filtered at $4-10 \mathrm{kHz}$ and sampled at $10-50 \mathrm{kHz}$. Liquid junction potentials were measured ( $13 \mathrm{mV}$ for K-gluconate-based and $10 \mathrm{mV}$ for Cs-methanesulfonate-based internal solutions) and adjusted appropriately. Resting membrane potential was determined in current clamp with zero holding current. Membrane conductance was measured using current ramps ( -100 to $+100 \mathrm{pA}$ at a duration of $100 \mathrm{~ms}$ ) under current-clamp mode.

Drugs. Drugs were obtained from Alomone Labs (apamin, 1-EBIO), Abcam [(R)-CPP, TTX], and Sigma-Aldrich (all others). Drugs were stored as aqueous stock solutions at $-20^{\circ} \mathrm{C}$ and dissolved in aCSF immediately before experiments. Drug solutions were applied by bath perfusion or pressure ejection ("puff").

Analysis. Data were analyzed using Clampfit (Molecular Devices) and Igor (WaveMetrics). The spontaneous transient outward currents were sampled by template matching using a rise time of $10 \mathrm{~ms}$ and decay of $20 \mathrm{~ms}$, threshold of $4 \times$ noise SD, using Axograph X. The voltage threshold of SK activation was detected under voltage-ramp protocols. The detection threshold for activation of SK current was determined from a $200-\mathrm{Hz}$-filtered trace by extrapolating a line fitted between -100 and $-90 \mathrm{mV}$; the point of deviation from this line $(2 \times$ noise SD, typically by several picoamperes to be obvious by eye) was considered as the point of detectable activation of SK. Statistical significance was established using paired $t$ tests unless otherwise indicated. Data are expressed as mean \pm SEM.

\section{Results}

\section{A spontaneous transient outward current mediated by}

SK channels

Spontaneous transient outward currents (STOCs) were detected in rat MNTB neurons under whole-cell voltage-clamp recordings with a K-gluconate-based internal solution (Fig. 1). At $-65 \mathrm{mV}$, these transient outward currents had an average amplitude of $65.3 \pm 1.0 \mathrm{pA}$, a $10-90 \%$ rise time of $8.8 \pm 0.1 \mathrm{~ms}$, and decay time constant of $17.4 \pm 0.2 \mathrm{~ms}(n=11)$. The STOCs were resistant to
$\mathrm{Na}^{+}$channel blocker TTX; blockers for ionotropic AMPA, NMDA, GABA, and glycine receptors; and blockers for metabotropic glutamate, $\mathrm{GABA}_{\mathrm{B}}$, muscarinic acetylcholine, and dopamine receptors (data not shown). Instead, $100 \mathrm{~nm}$ apamin, a peptide that specifically blocks SK channels (Adelman et al., 2012), completely suppressed the STOCs (Fig. $1 A, C$; $p=0.004, n=8)$, indicating the involvement of SK channels in mediating the STOCs. We also tested the effects of 1-EBIO, an SK-channel opener that enhances calcium sensitivity of SK channels (Pedarzani et al., 2001; Mateos-Aparicio et al., 2014), on the STOCs. 1-EBIO (100 $\mu \mathrm{M})$ increased the frequency from $0.54 \pm 0.20$ to $1.20 \pm 0.38 \mathrm{~Hz}(p=0.03)$ and slowed the decay time constant from $14.7 \pm 1.1$ to $42.5 \pm 1.3 \mathrm{~ms}$ (Fig. $1 D-G ; p<0.0001, n=$ 5). Meanwhile the overall STOC amplitude was slightly decreased from $62.9 \pm 6.7$ to $45.9 \pm 4.3 \mathrm{pA}$ (Fig. $1 H ; p=0.005, n=5$ ). The amplitude distributions of STOCs were typically well fitted with a Gaussian function; 1-EBIO did not largely affect the amplitude of the existing STOCs but created an apparently new STOC group with smaller amplitude (Fig. 1I).

During early postnatal development, the presynaptic and postsynaptic components of the calyx of Held synapse undergoes a variety of morphological and functional changes. We then measured STOCs of the MNTB from rats of different ages (Fig. 2A). At P6, 40\% (8 of 20) MNTB neurons showed apparent STOCs (Fig. 2 B, C). After reaching peaks at P10-P11, both the amplitude and the frequency of the STOCs started to decline and, at P14, STOCs were detected in only 1 of 19 cells and no apparent STOCs were detected in P16 cells (Fig. 2B,C).

SK channels are activated by increases in cytosolic $\mathrm{Ca}^{2+}$. STOCs in smooth muscle cells and neurons are activated by $\mathrm{Ca}^{2+}$ sparks resulting from spontaneous $\mathrm{Ca}^{2+}$ release from internal $\mathrm{Ca}^{2+}$ stores (Nelson et al., 1995; Arima et al., 2001; Cui et al., 2004). We found that ryanodine, an opener of ryanodine receptor that depletes internal ryanodine-sensitive $\mathrm{Ca}^{2+}$ stores, blocked the STOCs of MNTB neurons (Fig. $3 A, B ; p=0.003, n=6$ ), indicating that the STOCs are triggered by the $\mathrm{Ca}^{2+}$ sparks caused by the opening of ryanodine receptor located in the endoplasmic reticulum. To test whether SK channels are close to their $\mathrm{Ca}^{2+}$ source, we next examined the effects of $\mathrm{Ca}^{2+}$ buffering on STOCs. When the MNTB neurons were broken into a pipette solution containing $1 \mathrm{~mm}$ EGTA (compared with $0.2 \mathrm{~mm}$ EGTA in the standard solution), both the frequency and the amplitude of the STOCs were gradually decreased (Fig. $3 C-E ; p=0.02, n=8$ ). When the pipette EGTA was increased to $10 \mathrm{~mm}$, the STOCs were fully eliminated (Fig. $3 F, G ; p=0.009, n=4$ ). These results indicate that SK channels are loosely coupled with $\mathrm{Ca}^{2+}$ sparks (Neher, 1998; Jones and Stuart, 2013). Ryanodine receptors can be activated by calcium-induced calcium release in neurons (Verkhratsky and Shmigol, 1996). We then tested whether $\mathrm{Ca}^{2+}$ influx through voltage-gated $\mathrm{Ca}^{2+}$ channels (VGCCs) is required for triggering STOCs. Bath-application of $100 \mu \mathrm{M}$ cadmium, a nonselective voltage-gated calcium channel blocker, decreased the STOC frequency from $0.54 \pm 0.15$ to $0.22 \pm 0.07 \mathrm{~Hz}$ (Fig. $3 \mathrm{H}, I ; p=0.04$, $n=7)$ and reduced the STOC amplitude from $55.9 \pm 7.0$ to $41.5 \pm 7.7 \mathrm{pA}$ (Fig. $3 J ; p=0.0007, n=7$ ). Therefore, $\mathrm{Ca}^{2+}$ influx through VGCCs facilitates the STOC activity. STOCs were then 

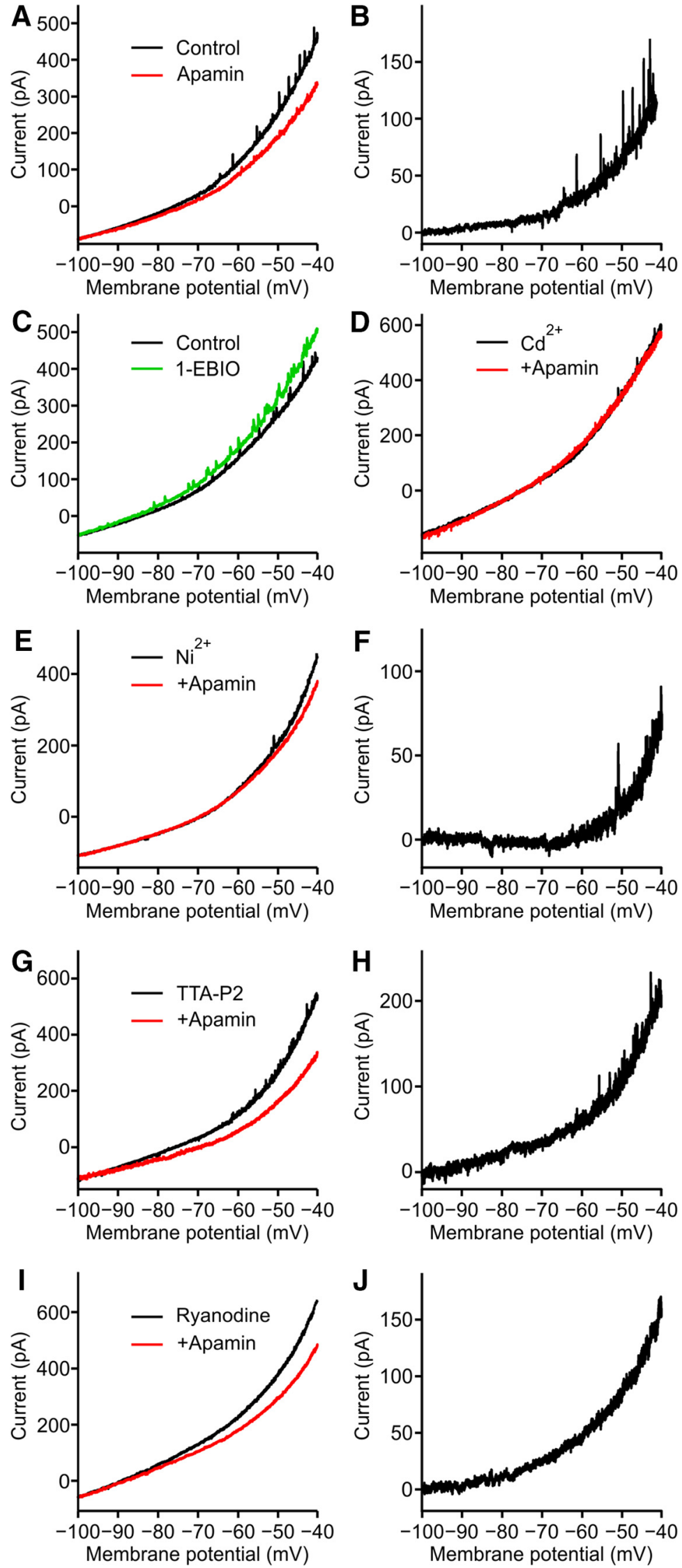

Figure 5. Activation of SK current. $A$, A slow voltage ramp $(5 \mathrm{mV} / \mathrm{s})$ evoked an outward current (black) that was partially blocked by $100 \mathrm{~nm}$ apamin (red). $\boldsymbol{B}$, Apamin-sensitive current, obtained by subtracting the red trace from the black in $\boldsymbol{A}$. Activation SK current was apparent at -85 mV.C, The voltage-ramp-evoked outward current was potentiated by $100 \mu \mathrm{m} 1$-EBIO. D, In the recorded at different holding potentials to test their voltage-dependence. When the cells were clamped at $-100 \mathrm{mV}$, which is close to the Nernst $\mathrm{K}^{+}$equilibrium potential $\left(E_{K}\right)$ of $-102 \mathrm{mV}$, no apparent STOCs were detected. Depolarizing the membrane potential gradually increased both the amplitude and the frequency of STOCs. At $\sim-50 \mathrm{mV}$, both the amplitude and the frequency reached their peaks. When the holding potential was further depolarized, however, the STOCs started to decline and disappeared at -30 $\mathrm{mV}$ (Fig. $3 K-M$ ).

\section{Activation of tonic SK current}

The decline of STOC amplitudes at depolarized voltages $(>-50 \mathrm{mV})$ was unexpected, as depolarization increases the $\mathrm{K}^{+}$ driving force. Indeed, the STOC amplitudes showed a linear relation with the $\mathrm{K}^{+}$ driving force $\left(E_{M}-E_{K}\right)$ in different types of neurons (Merriam et al., 1999; Arima et al., 2001; Klement et al., 2010). We hypothesized that SK channels are tonically activated at depolarizations and the STOCs are occluded by tonic SK activation. Voltage-step recordings were made in the presence of blockers of $\mathrm{Na}^{+}, \mathrm{Kvl}$, and HCN channels (see Materials and Methods; which allowed us to clamp the membrane potential over a wider range of values) to record the overall apaminsensitive SK currents (Fig. 4A,B). By subtracting traces with $100 \mathrm{nM}$ apamin from the control, a sustained current, in addition to STOCs, was detected (Fig. 4C; $n=$ 5 ). This tonic current had an amplitude of $81.9 \pm 21.0 \mathrm{pA}$ at $-40 \mathrm{mV}$. Thus, we concluded that SK channels are tonically activated when the MNTB neurons are depolarized.

SK channels do not desensitize and the open probability of these channels solely depends on the cytosolic $\mathrm{Ca}^{2+}$ (Hirschberg et al., 1998), allowing us to examine SK currents using voltage-ramp protocols. A slow voltage ramp $(5 \mathrm{mV} / \mathrm{s})$ from -100 to $-40 \mathrm{mV}$ evoked an outward current with STOCs rising at depolarized voltages (Fig. 5A). This outward current was partially suppressed by bath application of $100 \mathrm{~nm}$ apamin. By subtracting the

presence of $100 \mu \mathrm{m} \mathrm{Cd}^{2+}$, application of apamin did not affect the outward current. $\boldsymbol{E}$, In the presence of $100 \mu \mathrm{M} \mathrm{Ni}^{2+}$, outward current recorded in control and after application of apamin. $\boldsymbol{F}$, Apamin-sensitive current obtained by subtracting the red trace from the black in $\boldsymbol{E}$. $\mathbf{G}-\boldsymbol{J}$, Similar recordings as in $\boldsymbol{E}$ and $\boldsymbol{F}$, except in the presence of $2 \mu \mathrm{M} \operatorname{TTA}-\mathrm{P} 2(\boldsymbol{G}, \boldsymbol{H})$ or $20 \mu \mathrm{M}$ ryanodine $(\boldsymbol{I}, \boldsymbol{J})$. All recordings were made in the presence of TTX (0.5 $\mu \mathrm{M})$, margatoxin (10 nM), and CsCl (2 mm). 

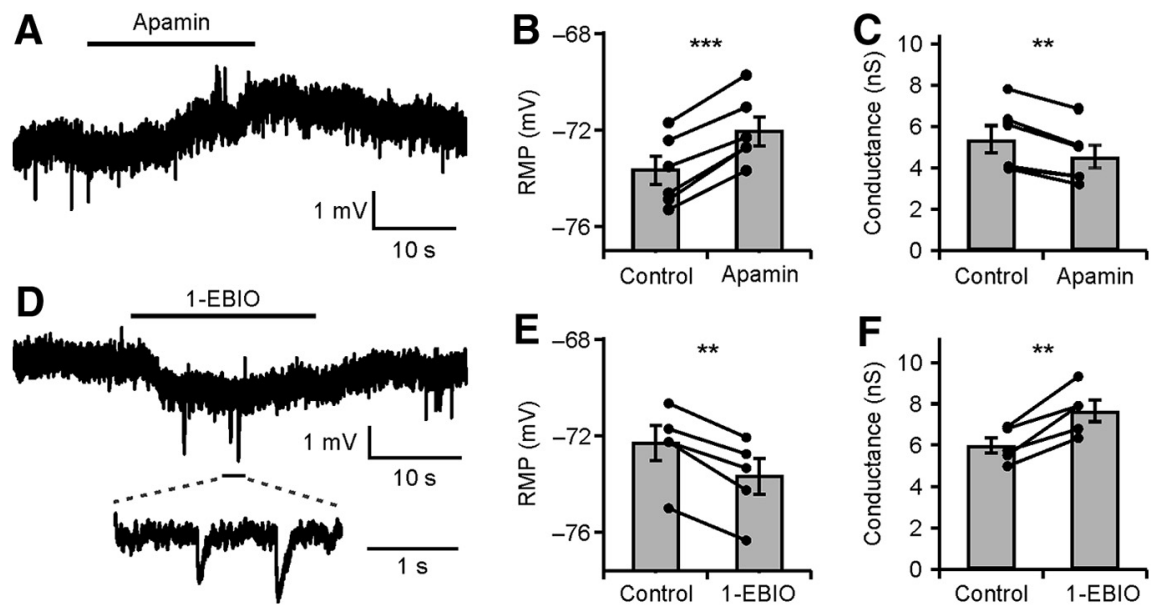

Figure 6. Effects of SK channels on resting membrane properties of MNTB neurons. $\boldsymbol{A}, \boldsymbol{B}$, Puff application of $1 \mu \mathrm{M}$ apamin depolarized the resting potential by $\sim 2 \mathrm{mV}$. C, Bath application of $100 \mathrm{~nm}$ apamin decreased the resting conductance. D, E, Puff application of $1 \mathrm{~mm} 1-\mathrm{EBIO}$ hyperpolarized the resting potential. $\boldsymbol{F}$, Bath application of $100 \mu \mathrm{M}$ 1-EBI0 increased resting conductance. ${ }^{* *} p<0.01 ;{ }^{* * *} p<0.001$; paired Student's $t$ test; error bars are mean \pm SEM. plication of $1 \mu \mathrm{M}$ apamin depolarized the resting membrane potential from $-73.7 \pm 0.6$ to $-72.1 \pm 0.6 \mathrm{mV}$ (Fig. $6 A, B ; p=0.0002, n=6)$. Meanwhile, the resting membrane conductance decreased from $5.4 \pm 0.7$ to $4.5 \pm 0.6$ nanosiemens (nS) (Fig. 6C; $p=0.002, n=6$ ).

By contrast, puff 1-EBIO (1 mM) hyperpolarized the membrane potential from $-72.4 \pm 0.7$ to $-73.8 \pm 0.7 \mathrm{mV}$ (Fig. $6 D, E ; p=0.001, n=5$ ) and increased the resting membrane conductance from $5.9 \pm 0.4$ to $7.6 \pm 0.5 \mathrm{nS}$ (Fig. $6 F ; p=0.006, n=5)$. Accompanying membrane potential hyperpolarization, transient voltage hyperpolarizations were also observed, indicating the activation of STOCs. We concluded that SK channels are partially open at the resting potential and contribute to resting potential and resting conductance. apamin trace from the control, a current-voltage relation of SK channels was determined (Fig. $5 B$ ). The tonic SK current had an amplitude of $90.9 \pm 20.4 \mathrm{pA}$ at $-40 \mathrm{mV}$ and the threshold for detection of current (see Materials and Methods) was remarkably negative $(-85.5 \pm 3.0 \mathrm{mV} ; n=6)$. By contrast, 1 -EBIO $(100 \mu \mathrm{M})$ enhanced the outward current for $110.6 \pm 20.6 \mathrm{pA}$ at $-40 \mathrm{mV}$ (Fig. $5 C ; n=4$ ). Since the voltage-insensitive SK channels are not activated by voltage per se (Adelman et al., 2012), the activation of SK channels may reflect the $\mathrm{Ca}^{2+}$ elevation by the activation of VGCCs. Indeed, apamin did not affect the outward current evoked by the same voltage ramp in the presence of $100 \mu \mathrm{M}$ cadmium (Fig. $5 D ; p=0.87, n=4$ ), indicating that the sustained SK current is activated by $\mathrm{Ca}^{2+}$ influx through VGCCs. Previous study showed that MNTB neurons express R-type, N-type, and $\mathrm{P} / \mathrm{Q}$-type, but not T-type, $\mathrm{Ca}^{2+}$ channels (Barnes-Davies et al., 2001). We then identified the VGCC subtypes that contribute to the SK activation. Low concentrations of $\mathrm{Ni}^{2+}(100 \mu \mathrm{M})$, specific for R-type and T-type channels (Wu et al., 1998; Kampa et al., 2006), shifted the activation threshold to $-62.3 \pm 0.9 \mathrm{mV}$ (Fig. $5 E, F ; n=7 ; p<0.001$, unpaired $t$ test). However, TTA-P2 (2 $\mu \mathrm{M})$, a specific T-type blocker, did not affect the activation threshold (Fig. $5 G, H ;-80.3 \pm 7.0 \mathrm{mV} ; n=5 ; p=0.51$, unpaired $t$ test). These data indicate that calcium-permeable ion channels sensitive to $\mathrm{Ni}^{2+}$ and $\mathrm{Cd}^{2+}$, likely $\mathrm{R}$-type $\mathrm{Ca}^{2+}$ channels, control the tonic activation of SK channels at or around resting membrane potentials.

We next tested whether ryanodine-sensitive $\mathrm{Ca}^{2+}$ stores are required for the tonic SK activation. In the presence of $20 \mu \mathrm{M}$ ryanodine, neither the threshold $(-80.4 \pm 6.6 \mathrm{mV} ; n=5 ; p=0.50$, unpaired $t$ test $)$ nor amplitude $(122.1 \pm 12.36 \mathrm{pA}$ at $-40 \mathrm{mV} ; n=5$; $p=0.25$, unpaired $t$ test) of the tonic SK current is changed (Fig. $5 I, J)$, suggesting that VGCCs, rather than calcium release from stores, are the $\mathrm{Ca}^{2+}$ sources to generate the tonic SK current.

\section{SK channels contribute to resting membrane potential and conductance}

The resting membrane potential of the MNTB neurons is typically -60 to $-75 \mathrm{mV}$ (Banks and Smith, 1992; Brew and Forsythe, 1995). Given that we detected the activation of SK current at $-85 \mathrm{mV}$, one would expect that some channels should be open at the resting membrane potential and contribute to resting properties. Under current clamp, we found indeed that puff ap-

\section{SK currents modulate signal responsiveness}

Since SK channels are activated at resting membrane potential and contribute to resting conductance, we predicted that SK channels would modulate the response to stimulation. We injected MNTB neurons with current waveforms of different amplitudes to generate depolarizations (Fig. 7). Application of 100 nM apamin resulted in a $20 \%$ increase in the amplitude of the voltage response $(n=5$; Fig. $7 A-E)$. These results indicate that the effectiveness of subthreshold signaling is regulated by the activity of SK channels.

\section{Activation of SK channels by NMDA receptors}

SK channels are activated by $\mathrm{Ca}^{2+}$ through NMDA receptors in hippocampal and cortex neurons (Faber et al., 2005; Ngo-Anh et al., 2005; Faber, 2010). Electrical stimulation was used to evoke presynaptic glutamate release and postsynaptic currents were recorded. We found that apamin enhanced the synaptically activated postsynaptic NMDA current (Fig. $8 A, B ; p=0.004, n=5$ ). By subtracting the apamin trace from the control, we obtained a NMDA-receptor-activated SK current of $243.8 \pm 56.4 \mathrm{pA}$ ( $n=$ 5). However, the postsynaptic AMPA current was not affected when $\mathrm{Cs}^{+}$-based pipette solution contained $5 \mathrm{~mm}$ EGTA (Fig. $8 C, D ; p=0.34, n=5)$, indicating that SK channels did not affect presynaptic glutamate release. We also tested how SK channels modulate the EPSP. To prevent spiking, 2 mM QX-314 was added into the pipette solution. Incubation of apamin $(100 \mathrm{nM})$ increased the EPSP amplitude from $24.0 \pm 3.8$ to $27.6 \pm 3.6 \mathrm{mV}$ (Fig. $8 E, F ; p=0.009, n=7$ ). Thus, $\mathrm{Ca}^{2+}$ influx through NMDA receptors activates SK channels, shunts the EPSP, and regulates the synaptic efficacy.

\section{Activation of SK channels during action potential}

In the presence of blockers for $\mathrm{Na}^{+}, \mathrm{Kv1}$, and $\mathrm{HCN}$ channel, a brief $1 \mathrm{~ms}$ voltage step from -80 to $+10 \mathrm{mV}$ was used to study the SK activation during action potential. This artificial spike triggered an inward $\mathrm{Ca}^{2+}$ current followed by an outward $\mathrm{K}^{+}$ current. Bath application of $100 \mathrm{nM}$ apamin significantly reduced the afterhyperpolarization current. Subtracting of the apamin trace from the control, an outward SK current was detected, 

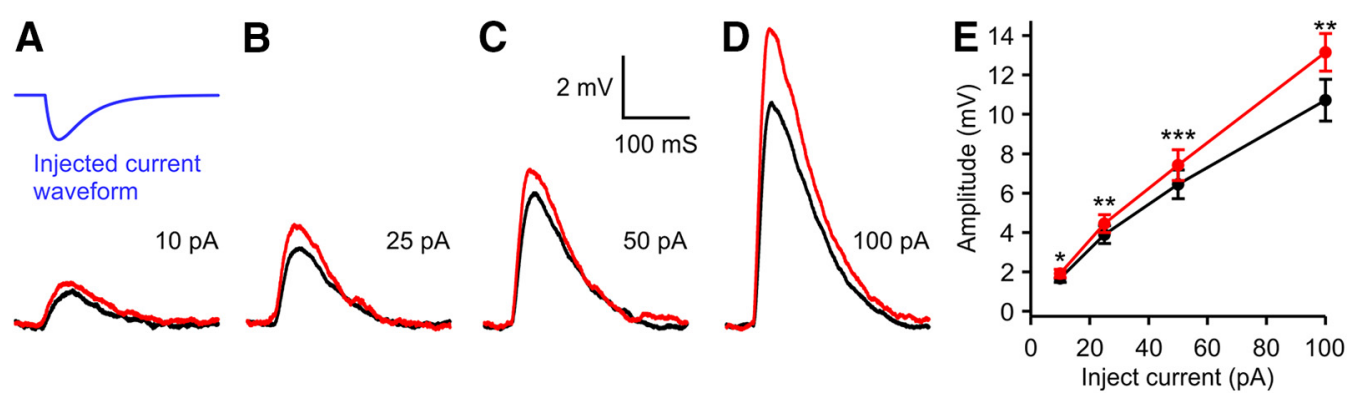

Figure 7. Effects of SK channels on responsiveness. $\boldsymbol{A}-\boldsymbol{D}$, Voltage responses to synaptic-like waveforms (rise time constant, $7.5 \mathrm{~ms}$; decay time constant, $25 \mathrm{~ms}$; $\boldsymbol{A}$, top trace) of different amplitudes injected into the MNTB neuron at control (black) or after bath application of $100 \mathrm{~nm}$ apamin (red). Voltage response traces were averages of $4-8$ repeats. $\boldsymbol{E}$, Statistical data summarizing the apamin effects on the response amplitudes in $\boldsymbol{A}-\boldsymbol{D}(n=5) .{ }^{*} p<0.05 ;{ }^{* *} p<0.01$; ${ }^{* *} p<0.001$; paired Student's $t$ test; error bars are mean \pm SEM.

A
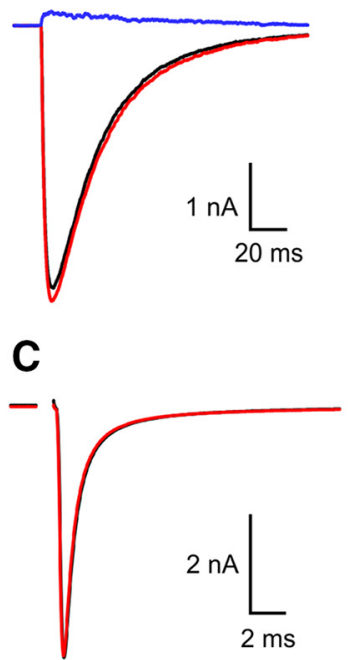

E

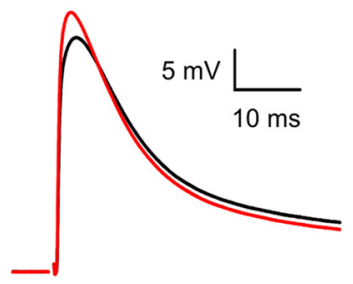

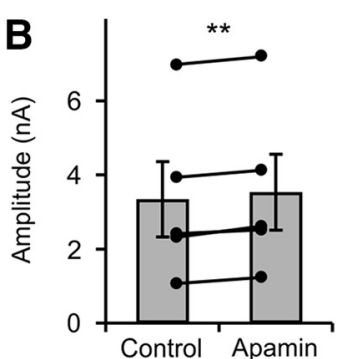
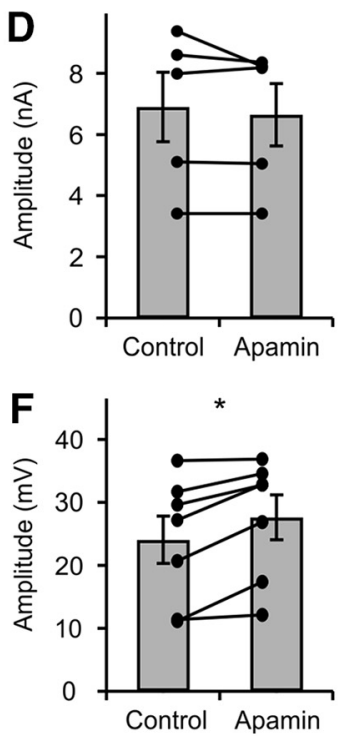

Figure 8. Activation of SK channels by $\mathrm{Ca}^{2+}$ influx through NMDA receptors. $\boldsymbol{A}, \boldsymbol{B}$, Under voltage clamp and using extracellular $\mathrm{Mg}^{2+}$-free and $\mathrm{K}^{+}$-based internal solution, $100 \mathrm{~nm}$ apamin potentiated the NMDA receptor-mediated postsynaptic current. The blue trace in $\boldsymbol{A}$ represents NMDA-receptor-activated SK current obtained by subtracting the red trace from the black trace. $\boldsymbol{C}, \boldsymbol{D}$, With $5 \mathrm{~mm}$ EGTA, $\mathrm{Cs}^{+}$-based internal solution, the AMPA-receptor-mediated EPSC was not affected by apamin (100 nm). E, $\boldsymbol{F}$, Representative traces of EPSP before and after apamin (100 nm) application. Two micromole QX-314 was added into the pipette solution. ${ }^{*} p<$ $0.05 ;{ }^{* *} p<0.01 ;{ }^{* * *} p<0.001$; paired Student's $t$ test; error bars are mean \pm SEM.

which started during the depolarizing pulse, peaked at $8.4 \pm 2.8 \mathrm{~ms}$ with an amplitude of $85.5 \pm 19.2 \mathrm{pA}$, and decayed with a time constant of $9.1 \pm 1.2 \mathrm{~ms}$ (Fig. $9 A ; n=7$ ).

Next, we examined how SK channels affect the waveform of synaptically evoked action potentials. Presynaptic afferent fiber stimulation enabled us to record reliable and stable action potentials in MNTB neurons. Bath application of $100 \mathrm{nM}$ apamin depolarized the afterpotential by $5.2 \pm 0.6 \mathrm{mV}$ (Fig. $9 B ; n=6$ ).
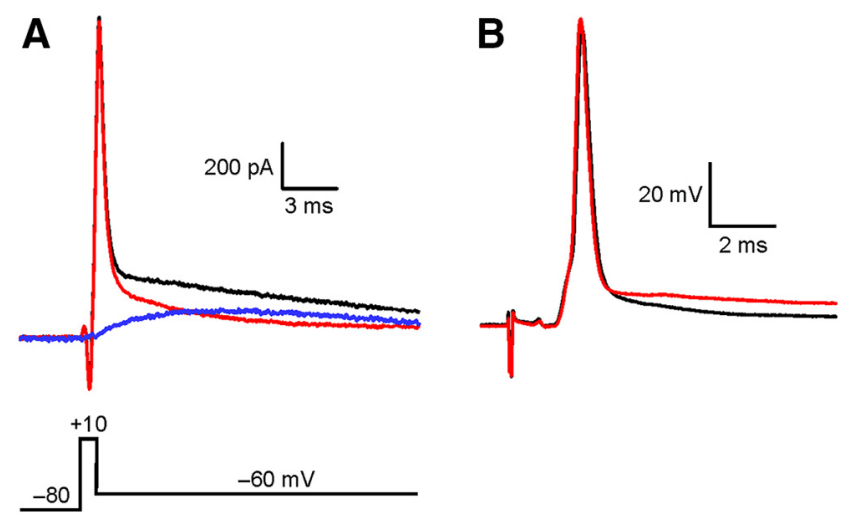

Figure 9. Activation of SK channels during action potential. $A, A$ brief voltage step to $+10 \mathrm{mV}$ was used to mimic the action potential evoked current. The current was recorded in control condition (black) and after bath application of $100 \mathrm{~nm}$ apamin (red). The blue trace represented the apamin-sensitive current. Recordings were made in the presence of $0.5 \mu \mathrm{m}$ TTX, $10 \mathrm{~nm}$ margatoxin, and $2 \mathrm{~mm} \mathrm{CSCl.} \mathrm{B,} \mathrm{Presynaptic} \mathrm{fiber} \mathrm{stimulation-evoked} \mathrm{action} \mathrm{potentials}$ recorded in control (black) and after bath application of $100 \mathrm{~nm}$ apamin (red). Recordings were made in the presence of strychnine $(1 \mu \mathrm{m})$ and picrotoxin $(50 \mu \mathrm{m})$ to block glycinergic and GABAergic synaptic transmission.

\section{SK currents regulate reliability of signal transmission}

Globular bushy cells fire action potentials up to hundreds of hertz during sound stimulation. The high-frequency signals of globular bushy cells are faithfully transmitted to the postsynaptic MNTB neurons through the giant glutamatergic synapse, the calyx of Held, with few or no failures (Mc Laughlin et al., 2008; Lorteije et al., 2009). To test whether SK-channel activity plays a crucial role in maintaining faithful one-to-one signaling, we stimulated the presynaptic fiber and recorded the postsynaptic response. At $100 \mathrm{~Hz}$, each presynaptic stimulation evoked an action potential in MNTB neurons under control conditions (Fig. 10A). Bath application with apamin disrupted the one-toone reliability and one presynaptic stimulation started to trigger two spikes in postsynaptic MNTB neurons after a few spikes (Fig. $10 B)$, suggesting that the spike-activated SK current is critical in controlling MNTB excitability and preventing the firing of extra spikes.

A previous study showed that upon blocking Kv1 channels with dendrotoxin, a single stimulus could evoke multiple presynaptic action potentials and multiple EPSCs in MNTB neurons (Dodson et al., 2003). This led us to test whether apamin affects the presynaptic release during stimulation train. Bath application of apamin (100 nM) did not affect the one-to-one release and each stimulus evoked a single EPSC during the whole stimulation train (Fig. 10C,D). Together with Figure 6, these results confirmed that 
A Control, $100 \mathrm{~Hz}$ stimuli
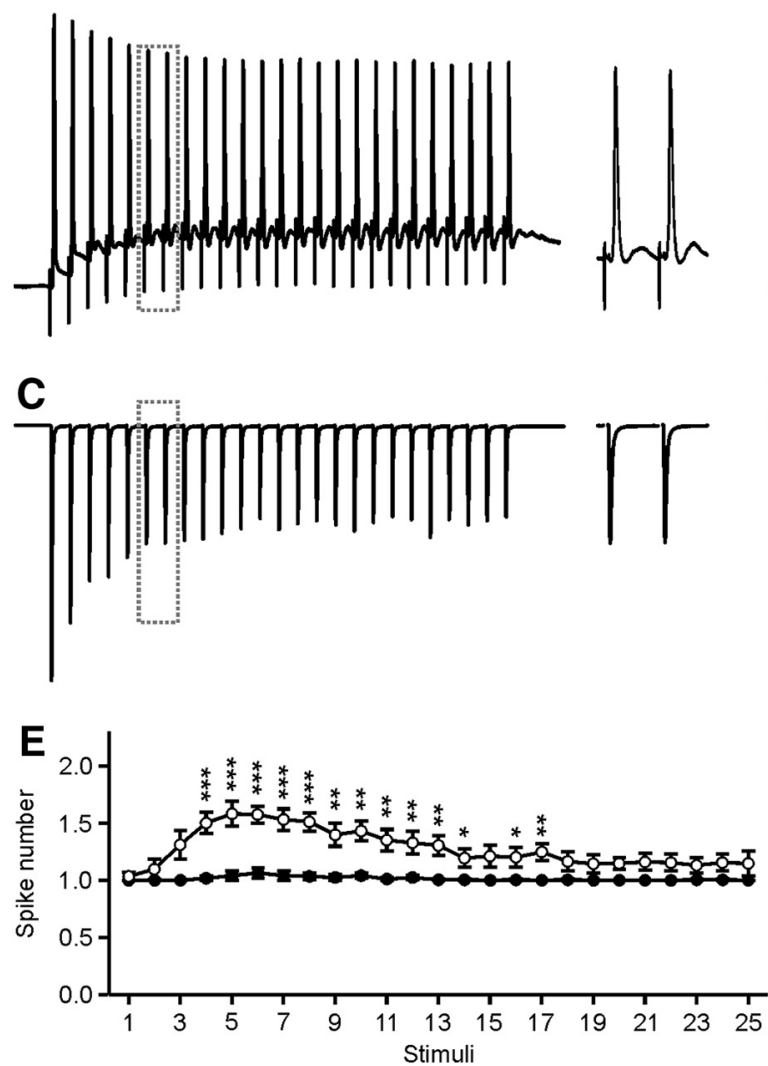

B Apamin, $100 \mathrm{~Hz}$ stimuli

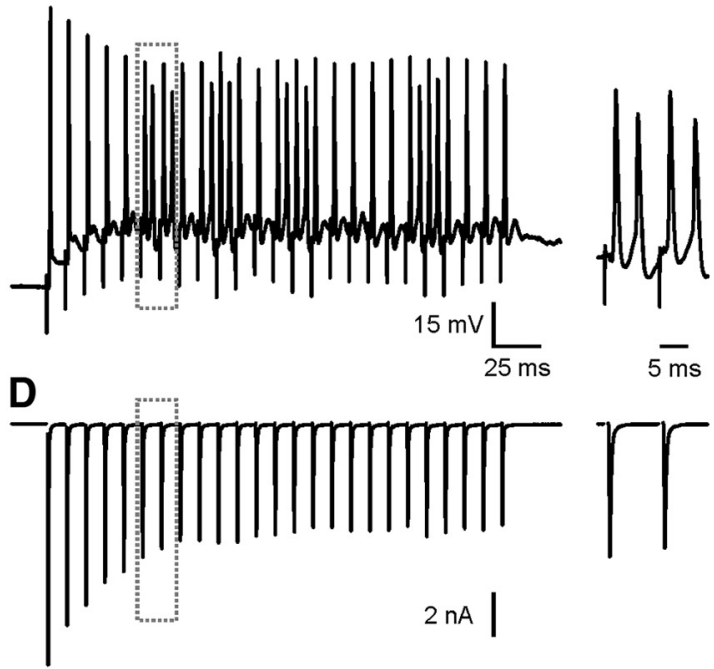

$\mathbf{F}$

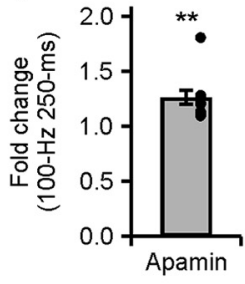

Figure 10. SK-channel activation was required for highly reliable signal transmission. $A$, Representative trace showing presynaptic $100 \mathrm{~Hz}$ stimulation generated a train of action potentials in postsynaptic MNTB neurons. $\boldsymbol{B}$, Bath perfusion with apamin (100 nM). The stimulation generated extra action potentials in MNTB neurons. $\boldsymbol{C}, \boldsymbol{D}$, EPSC recordings following $100 \mathrm{~Hz}$ stimulation in control $(\boldsymbol{C})$ and with apamin $(\boldsymbol{D})$. $\boldsymbol{E}$, Spike number counts after each stimulation before and after apamin application $(n=10)$. $\boldsymbol{F}$, Summary data that apamin increased the overall postsynaptic spiking in response to presynaptic stimulation. ${ }^{*} p<0.05 ;{ }^{* *} p<0.01 ;{ }^{* * *} p<0.001$; paired Student's $t$ test; error bars are mean \pm SEM.

apamin does not change the presynaptic firing properties or glutamate release.

\section{Discussion}

In this study, we demonstrated a potassium conductance mediated by SK channels in rat MNTB neurons. SK channels are transiently activated by $\mathrm{Ca}^{2+}$ sparks and mediate the STOCs. SK channels can be also tonically activated by $\mathrm{Ca}^{2+}$ influx through VGCCs. Surprisingly, the tonic activation of SK channels controls the resting membrane potential and conductance, and thus the response of MNTB neurons to signal inputs. Moreover, SK channels are activated by $\mathrm{Ca}^{2+}$ influx through NMDA receptors and regulates the synaptic efficacy. Lastly, SK channels are activated by $\mathrm{Ca}^{2+}$ influx during action potentials and control the afterpotential and neuronal excitability. Blocking of SK channels disrupts the one-to-one signal transmission from the presynaptic calyces to the postsynaptic MNTB neurons. These data revealed that SK channels play important roles in controlling the resting properties and in ensuring the reliable and precise signal transmission in the MNTB neurons.

\section{Activation of SK channels at MNTB neurons}

While SK-channel subunits share the similar architecture and serpentine transmembrane topology of voltage-gated $\mathrm{K}^{+}$channels, these channels are voltage-independent $\mathrm{K}^{+}$channels activated solely by cytosolic $\mathrm{Ca}^{2+}$ (Blatz and Magleby, 1986; Xia et al., 1998). The elevations in cytosolic $\mathrm{Ca}^{2+}$ could result from several different sources, including $\mathrm{Ca}^{2+}$ influx through voltage- gated $\mathrm{Ca}^{2+}$ channels, $\mathrm{Ca}^{2+}$ influx via $\mathrm{Ca}^{2+}$-permeable ligandgated ion channels, $\mathrm{Ca}^{2+}$ released from intracellular $\mathrm{Ca}^{2+}$ stores, and $\mathrm{Ca}^{2+}$-induced $\mathrm{Ca}^{2+}$ release (Adelman et al., 2012). We found that SK channels in the MNTB neurons could be activated by all these $\mathrm{Ca}^{2+}$ sources.

SK channels were transiently activated by $\mathrm{Ca}^{2+}$ sparks and mediate STOCs (Figs. 1, 3). The nonselective VGCC blocker cadmium reduced the STOC amplitude and frequency, indicating that $\mathrm{Ca}^{2+}$ influx via $\mathrm{Ca}^{2+}$ channels facilitates STOC activity. However, blocking VGCCs failed to completely block STOCs, with $40 \%$ of STOCs remaining in the presence of cadmium. Ryanodine, however, fully abolished the STOCs at different voltages (Fig. 5I), suggesting that $\mathrm{Ca}^{2+}$ stores are essential and VGCCs indirectly modulate for STOCs. Thus, both spontaneous intracellular $\mathrm{Ca}^{2+}$ release and $\mathrm{Ca}^{2+}$-induced $\mathrm{Ca}^{2+}$ release activate SK channels and mediate STOCs. The STOCs appear at $\sim \mathrm{P} 6$ and start to disappear at P14. The decline of STOCs after hearing onset may reflect the decline of SK channels, the decline of $\mathrm{Ca}^{2+}$ sparks, or the looser coupling between $\mathrm{Ca}^{2+}$ sparks and SK channels. Further experiment is necessary to clarify the mechanisms for development change of STOCs.

The amplitude distributions of STOCs were fitted with a Gaussian function (Fig. 1) while the SK channel opener 1-EBIO created an apparently new STOC group with smaller amplitude, suggesting the heterogeneous $\mathrm{Ca}^{2+}$ sparks in $\mathrm{MNTB}$ neurons. At control conditions, only big $\mathrm{Ca}^{2+}$ sparks triggered STOCs while 1 -EBIO increased the $\mathrm{Ca}^{2+}$ sensitivity of SK channels and small 
$\mathrm{Ca}^{2+}$ sparks were then able to activate SK channels and trigger STOCs. We found that lower-affinity $\mathrm{Ca}^{2+}$ chelator EGTA at 1 $\mathrm{mm}$ significantly decreased the frequency and the amplitude of the STOCs and 10 mM EGTA eliminated all STOCs (Fig. 3), indicating the loose coupling of $\mathrm{Ca}^{2+}$ sparks and SK channels at microdomains (Neher, 1998; Jones and Stuart, 2013). It is interesting that 1-EBIO did not affect the amplitude of the existing STOCs (Fig. 1I). A possible explanation is that at peak concentration, big $\mathrm{Ca}^{2+}$ sparks may saturate SK channels. Indeed, studies in hippocampal and cortical pyramidal neurons showed that $\mathrm{Ca}^{2+}$ sparks could extend to $>5 \mu \mathrm{m}$ and reach peak concentration of $>5 \mu \mathrm{M}$ (Ross, 2012).

\section{SK channels and membrane properties}

SK channels are extensively expressed in the nervous system and are gated by submicromolar concentrations of intracellular $\mathrm{Ca}^{2+}$ ions with a half-maximal activation concentration of $0.1-1 \mu \mathrm{M}$ (Köhler et al., 1996; Joiner et al., 1997; Xia et al., 1998; Pedarzani et al., 2001). The activation of SK channels requires elevated levels of cytosolic $\mathrm{Ca}^{2+}$, such as $\mathrm{Ca}^{2+}$ influx during firing action potentials. Under resting membrane potential, however, the cytosolic $\mathrm{Ca}^{2+}$ level is usually low and SK channels are not active (Adelman et al., 2012). By contrast, our data in the MNTB neurons showed that SK channels were partially activated at resting membrane potentials. We detected a tonic SK current that starts to activate at $\sim-85 \mathrm{mV}$ (Fig. $5 B$ ), a voltage below the resting membrane potentials of -60 to $-75 \mathrm{mV}$ (Banks and Smith, 1992; Brew and Forsythe, 1995). Because SK channels are not activated by voltage per se (Adelman et al., 2012), the activation of SK channels should reflect the cytosolic $\mathrm{Ca}^{2+}$ elevation during the activation of VGCCs. Indeed, the tonic SK current was fully abolished by $100 \mu \mathrm{M}$ cadmium (Fig. 5D). Consistent with that MNTB neurons express R-, N-, and P/Q-, but not T-type, $\mathrm{Ca}^{2+}$ channels (Barnes-Davies et al., 2001), we did not detect the contribution of T-type (Fig. $5 H$ ). Meanwhile $100 \mu \mathrm{M} \mathrm{Ni}^{2+}$, a concentration believed to be specific for R- and T-type channels (Wu et al., 1998; Kampa et al., 2006), shifted the activation threshold, suggesting that R-type $\mathrm{Ca}^{2+}$ channels is involved in the SK activation at voltages below $-60 \mathrm{mV}$, although intermediate voltage-activated R-type channels are usually activate at more depolarized voltages. Alternatively, other calcium-permeable ion channels that sensitive to $\mathrm{Cd}^{2+}$ and $\mathrm{Ni}^{2+}$ may be responsible for the tonic activation of SK channels. At more depolarized voltages, the high-voltage gated N-type and P/Q-types would be involved.

The background conductance of MNTB neurons is mainly determined by two-pore potassium leak channels (Berntson and Walmsley, 2008). We found here that that SK channels play a significant role in resting membrane properties of MNTB neurons, a result dependent entirely on the activation of SK channels at hyperpolarized voltages. Apamin depolarized the resting membrane potential and decreased the membrane conductance of MNTB neurons. Interestingly, in the calyx-MNTB synapse, totally different ion channels are involved in determining the resting membrane potential and conductance at the presynaptic and postsynaptic components. At the calyceal terminals, voltagegated $\mathrm{Na}^{+}, \mathrm{KCNQ}$, and $\mathrm{HCN}$ channels contribute to the resting conductance (Cuttle et al., 2001; Huang and Trussell, 2008, 2011).

\section{SK channels subserve auditory function}

GBCs fire action potentials reliably and precisely synchronize to sound. For example, GBCs with characteristic frequency of 700 $\mathrm{Hz}$ entrain to the sound and fire an action potential to every stimulus cycle with a phase-locking value of 0.99 (Joris et al., 1994). High-frequency signals of GBCs reliably transmit to the target MNTB neuron through the calyx of Held synapse (von Gersdorff and Borst, 2002). Several cellular mechanisms have been established that are important for supporting neurotransmission at such high rates, including presynaptic ion channels that enable reliable presynaptic spike waveform and calcium influx; large readily releasable pool, many release sites, and low release probability that enhance the release reliability; as well as fast kinetics of postsynaptic AMPA-type glutamate receptors that allow fast and faithful transmission to the postsynaptic MNTB (Taschenberger and von Gersdorff, 2000; Taschenberger et al., 2002; Wu et al., 2009; Borst and Soria van Hoeve, 2012). Moreover, different voltage-gated $\mathrm{K}^{+}$channels are expressed on the presynaptic and postsynaptic components to control the neuronal excitability, determine spike shape, and enable high-frequency firing (Brew and Forsythe, 1995; Wang et al., 1998; Dodson et al., 2002; Ishikawa et al., 2003; Dodson and Forsythe, 2004; Huang and Trussell, 2011; Yang et al., 2014).

We found that SK channels are activated by $\mathrm{Ca}^{2+}$ through NMDA receptors in the MNTB neurons. The activation of SK channels partially offsets the EPSC and shunted the EPSP, thus regulating the synaptic efficacy. SK channels are activated by $\mathrm{Ca}^{2+}$ influx during a single or a burst of action potentials and mediate the afterhyperpolarization, thus controlling the intrinsic excitability in many neurons for setting the firing frequency and adaptation (Adelman et al., 2012). Here we measured the single action potential-triggered SK current in MNTB neurons. This 85 pA SK current peaked at a few milliseconds, lasted for tens of milliseconds, and mediated the medium afterhyperpolarization (Fig. 9). The calyx-MNTB synapse is a relay that transfers the presynaptic spike to the postsynaptic site and each presynaptic action potential evoked one action potential in the MNTB neurons. The evoked postsynaptic action potentials displayed a distinct afterdepolarization. During $100 \mathrm{~Hz}$ firing, the afterdepolarization accumulated and substantially depolarized the membrane potential (Fig. 10). The relatively slow kinetics allow SK current summation during $100 \mathrm{~Hz}$ firing, thus counteracting the afterdepolarization and stabilizing the overall excitability. Interestingly, the activation of SK channels is required to maintain the reliable signaling at high frequency. Bath application of apamin disrupted the one-to-one reliability and each presynaptic stimulus started to trigger two postsynaptic spikes after a few spikes at $100 \mathrm{~Hz}$ stimulation (Fig. 10), while the reliability was not affected when the presynaptic stimulation is at $10 \mathrm{~Hz}$ (data not shown). This activity-dependent activation of the SK channel is different from that of voltage-gated $\mathrm{K}^{+}$channels, such as $\mathrm{Kv} 1$ channels. Blocking Kv1 channels changes the overall excitability and each presynaptic action potential triggers multiple postsynaptic spikes no matter the firing frequency (Brew and Forsythe, 1995).

\section{References}

Adelman JP, Maylie J, Sah P (2012) Small-conductance Ca2+-activated K+ channels: form and function. Annu Rev Physiol 74:245-269. CrossRef Medline

Arima J, Matsumoto N, Kishimoto K, Akaike N (2001) Spontaneous miniature outward currents in mechanically dissociated rat Meynert neurons. J Physiol 534:99-107. CrossRef Medline

Banks MI, Smith PH (1992) Intracellular recordings from neurobiotinlabeled cells in brain slices of the rat medial nucleus of the trapezoid body. J Neurosci 12:2819-2837. Medline

Barnes-Davies M, Owens S, Forsythe ID (2001) Calcium channels triggering transmitter release in the rat medial superior olive. Hear Res 162:134145. CrossRef Medline

Berntson AK, Walmsley B (2008) Characterization of a potassium-based 
leak conductance in the medial nucleus of the trapezoid body. Hear Res 244:98-106. CrossRef Medline

Blatz AL, Magleby KL (1986) Single apamin-blocked Ca-activated K+ channels of small conductance in cultured rat skeletal muscle. Nature 323:718-720. CrossRef Medline

Borst JG, Soria van Hoeve J (2012) The calyx of Held synapse: from model synapse to auditory relay. Annu Rev Physiol 74:199-224. CrossRef Medline

Brew HM, Forsythe ID (1995) Two voltage-dependent K+ conductances with complementary functions in postsynaptic integration at a central auditory synapse. J Neurosci 15:8011-8022. Medline

Cui G, Okamoto T, Morikawa H (2004) Spontaneous opening of T-type $\mathrm{Ca}^{2+}$ channels contributes to the irregular firing of dopamine neurons in neonatal rats. J Neurosci 24:11079-11087. CrossRef Medline

Cuttle MF, Rusznák Z, Wong AY, Owens S, Forsythe ID (2001) Modulation of a presynaptic hyperpolarization-activated cationic current $(\mathrm{I}(\mathrm{h}))$ at an excitatory synaptic terminal in the rat auditory brainstem. J Physiol 534: 733-744. CrossRef Medline

Dodson PD, Forsythe ID (2004) Presynaptic K+ channels: electrifying regulators of synaptic terminal excitability. Trends Neurosci 27:210-217. CrossRef Medline

Dodson PD, Barker MC, Forsythe ID (2002) Two heteromeric Kv1 potassium channels differentially regulate action potential firing. J Neurosci 22:6953-6961. Medline

Dodson PD, Billups B, Rusznák Z, SzûcsG, Barker MC, Forsythe ID (2003) Presynaptic rat Kv1.2 channels suppress synaptic terminal hyperexcitability following action potential invasion. J Physiol 550:27-33. CrossRef Medline

Faber ES (2010) Functional interplay between NMDA receptors, SK channels and voltage-gated $\mathrm{Ca} 2+$ channels regulates synaptic excitability in the medial prefrontal cortex. J Physiol 588:1281-1292. CrossRef Medline

Faber ES, Delaney AJ, Sah P (2005) SK channels regulate excitatory synaptic transmission and plasticity in the lateral amygdala. Nat Neurosci 8:635641. CrossRef Medline

Grothe B, Pecka M, McAlpine D (2010) Mechanisms of sound localization in mammals. Physiol Rev 90:983-1012. CrossRef Medline

Hirschberg B, Maylie J, Adelman JP, Marrion NV (1998) Gating of recombinant small-conductance Ca-activated $\mathrm{K}+$ channels by calcium. J Gen Physiol 111:565-581. CrossRef Medline

Huang H, Trussell LO (2008) Control of presynaptic function by a persistent $\mathrm{Na}(+)$ current. Neuron 60:975-979. CrossRef Medline

Huang H, Trussell LO (2011) KCNQ5 channels control resting properties and release probability of a synapse. Nat Neurosci 14:840-847. CrossRef Medline

Huang H, Trussell LO (2014) Presynaptic HCN channels regulate vesicular glutamate transport. Neuron 84:340-346. CrossRef Medline

Ishikawa T, Nakamura Y, Saitoh N, Li WB, Iwasaki S, Takahashi T (2003) Distinct roles of Kv1 and Kv3 potassium channels at the calyx of Held presynaptic terminal. J Neurosci 23:10445-10453. Medline

Joiner WJ, Wang LY, Tang MD, Kaczmarek LK (1997) hSK4, a member of a novel subfamily of calcium-activated potassium channels. Proc Natl Acad Sci U S A 94:11013-11018. CrossRef Medline

Jones SL, Stuart GJ (2013) Different calcium sources control somatic versus dendritic SK channel activation during action potentials. J Neurosci 33: 19396-19405. CrossRef Medline

Joris PX, Carney LH, Smith PH, Yin TC (1994) Enhancement of neural synchronization in the anteroventral cochlear nucleus. I. Responses to tones at the characteristic frequency. J Neurophysiol 71:1022-1036. Medline

Kampa BM, Letzkus JJ, Stuart GJ (2006) Requirement of dendritic calcium spikes for induction of spike-timing-dependent synaptic plasticity. J Physiol 574:283-290. CrossRef Medline

Klement G, Druzin M, Haage D, Malinina E, Arhem P, Johansson S (2010) Spontaneous ryanodine-receptor-dependent $\mathrm{Ca} 2+$-activated $\mathrm{K}+$ currents and hyperpolarizations in rat medial preoptic neurons. J Neurophysiol 103:2900-2911. CrossRef Medline
Köhler M, Hirschberg B, Bond CT, Kinzie JM, Marrion NV, Maylie J, Adelman JP (1996) Small-conductance, calcium-activated potassium channels from mammalian brain. Science 273:1709-1714. CrossRef Medline

Lorteije JA, Rusu SI, Kushmerick C, Borst JG (2009) Reliability and precision of the mouse calyx of Held synapse. J Neurosci 29:13770-13784. CrossRef Medline

Mateos-Aparicio P, Murphy R, Storm JF (2014) Complementary functions of SK and Kv7/M potassium channels in excitability control and synaptic integration in rat hippocampal dentate granule cells. J Physiol 592:669693. CrossRef Medline

Mc Laughlin M, van der Heijden M, Joris PX (2008) How secure is in vivo synaptic transmission at the calyx of Held? J Neurosci 28:10206-10219. CrossRef Medline

Merriam LA, Scornik FS, Parsons RL (1999) Ca(2+)-induced $\mathrm{Ca}(2+)$ release activates spontaneous miniature outward currents (SMOCs) in parasympathetic cardiac neurons. J Neurophysiol 82:540-550. Medline

Neher E (1998) Vesicle pools and Ca2+ microdomains: new tools for understanding their roles in neurotransmitter release. Neuron 20:389-399. CrossRef Medline

Nelson MT, Cheng H, Rubart M, Santana LF, Bonev AD, Knot HJ, Lederer WJ (1995) Relaxation of arterial smooth muscle by calcium sparks. Science 270:633-637. CrossRef Medline

Ngo-Anh TJ, Bloodgood BL, Lin M, Sabatini BL, Maylie J, Adelman JP (2005) SK channels and NMDA receptors form a Ca2+-mediated feedback loop in dendritic spines. Nat Neurosci 8:642-649. CrossRef Medline

Pedarzani P, Mosbacher J, Rivard A, Cingolani LA, Oliver D, Stocker M, Adelman JP, Fakler B (2001) Control of electrical activity in central neurons by modulating the gating of small conductance $\mathrm{Ca} 2+$-activated $\mathrm{K}+$ channels. J Biol Chem 276:9762-9769. CrossRef Medline

Ross WN (2012) Understanding calcium waves and sparks in central neurons. Nat Rev Neurosci 13:157-168. CrossRef Medline

Smith PH, Joris PX, Carney LH, Yin TC (1991) Projections of physiologically characterized globular bushy cell axons from the cochlear nucleus of the cat. J Comp Neurol 304:387-407. CrossRef Medline

Taschenberger H, von Gersdorff H (2000) Fine-tuning an auditory synapse for speed and fidelity: developmental changes in presynaptic waveform, EPSC kinetics, and synaptic plasticity. J Neurosci 20:9162-9173. Medline

Taschenberger H, Leão RM, Rowland KC, Spirou GA, von Gersdorff H (2002) Optimizing synaptic architecture and efficiency for highfrequency transmission. Neuron 36:1127-1143. CrossRef Medline

Tollin DJ (2003) The lateral superior olive: a functional role in sound source localization. Neuroscientist 9:127-143. CrossRef Medline

Trussell LO (1997) Cellular mechanisms for preservation of timing in central auditory pathways. Curr Opin Neurobiol 7:487-492. CrossRef Medline

Verkhratsky A, Shmigol A (1996) Calcium-induced calcium release in neurones. Cell Calcium 19:1-14. CrossRef Medline

von Gersdorff H, Borst JG (2002) Short-term plasticity at the calyx of Held. Nat Rev Neurosci 3:53-64. CrossRef Medline

Wang LY, Gan L, Forsythe ID, Kaczmarek LK (1998) Contribution of the Kv3.1 potassium channel to high-frequency firing in mouse auditory neurones. J Physiol 509:183-194. CrossRef Medline

Wu LG, Borst JG, Sakmann B (1998) R-type Ca2 + currents evoke transmitter release at a rat central synapse. Proc Natl Acad Sci U S A 95:47204725. CrossRef Medline

Wu XS, McNeil BD, Xu J, Fan J, Xue L, Melicoff E, Adachi R, Bai L, Wu LG (2009) $\mathrm{Ca}(2+)$ and calmodulin initiate all forms of endocytosis during depolarization at a nerve terminal. Nat Neurosci 12:1003-1010. CrossRef Medline

Xia XM, Fakler B, Rivard A, Wayman G, Johnson-Pais T, Keen JE, Ishii T, Hirschberg B, Bond CT, Lutsenko S, Maylie J, Adelman JP (1998) Mechanism of calcium gating in small-conductance calcium-activated potassium channels. Nature 395:503-507. CrossRef Medline

Yang YM, Wang W, Fedchyshyn MJ, Zhou Z, Ding J, Wang LY (2014) Enhancing the fidelity of neurotransmission by activity-dependent facilitation of presynaptic potassium currents. Nat Commun 5:4564. CrossRef Medline 